\title{
Hospital cost associated with anemia in elective colorectal surgery: a historical cohort study
}

\section{Les coûts hospitaliers associés à l'anémie lors d'une chirurgie colorectale non urgente: une étude de cohorte historique}

\author{
Simon Feng, MD • Joshua Greenberg, MD, MSc $\cdot$ Husein Moloo, MD, MSc • \\ Kednapa Thavorn, PhD • Daniel I. McIsaac, MD, MPH
}

Received: 21 September 2018/Revised: 28 November 2018/ Accepted: 20 January 2019/Published online: 1 May 2019

(C) Canadian Anesthesiologists' Society 2019

\begin{abstract}
Purpose Anemia is highly prevalent in the colorectal surgery population, affecting 30-70\% of patients. Anemia is associated with significant morbidity and mortality; however, there is a lack of evidence on how much anemia impacts healthcare costs. This study aims to determine the hospital cost of index surgical admission, postoperative length of stay, and transfusion rate associated with preoperative anemia in elective major colorectal surgery. Methods This historical cohort study included 851 adult inpatients having elective colorectal surgery at a tertiary care academic health sciences network between April 2010 and February 2016. Anemia was defined as hematocrit $\leq$ $39 \%$. The primary outcome was total hospital costs
\end{abstract}

This project was supported by a CAS Career Scientist Award to Dr. Daniel I. McIsaac.

Electronic supplementary material The online version of this article (https://doi.org/10.1007/s12630-019-01379-8) contains supplementary material, which is available to authorized users.

S. Feng, MD

Department of Anesthesiology and Pain Medicine, The Ottawa

Hospital and University of Ottawa, Ottawa, ON, Canada

J. Greenberg, MD, MSc

Department of Surgery, The Ottawa Hospital and University of

Ottawa, Ottawa, ON, Canada

H. Moloo, MD, MSc

Department of Surgery, The Ottawa Hospital and University of Ottawa, Ottawa, ON, Canada

Ottawa Hospital Research Institute, Ottawa, ON, Canada

K. Thavorn, $\mathrm{PhD}$

Ottawa Hospital Research Institute, Ottawa, ON, Canada standardized to 2016 CAD. Secondary outcomes were postoperative length of stay and transfusion. Multivariable regression analyses and propensity score methods were used to measure adjusted associations between anemia and outcomes.

Results Before surgery, $381 / 851$ (45\%) patients were anemic. The mean (standard deviation [SD]) cost of index admission for an elective colorectal surgery was 20,040 (23,219) CAD. Anemia was associated with an adjusted $14 \%$ relative increase in costs $195 \%$ confidence interval [CI], 6 to 23; $P<0.001)$. The total hospitalization cost attributable to anemia was 3,027 CAD (95\% CI, 2,670 to 3,388). Hospital costs and length of stay were highly associated; anemia was associated with an $18 \%$ increase in length of stay (95\% CI, 7 to 30; P<0.001) and increased transfusion rates (risk ratio, 4.7; 95\% CI, 2.71 to 8.33; $P<0.001)$.

Conclusion Over 2,600 CAD per index surgical admission is attributable to preoperative anemia. Preoperative

School of Epidemiology and Public Health, University of Ottawa, Ottawa, ON, Canada

D. I. McIsaac, MD, MPH ( $\square)$

Department of Anesthesiology and Pain Medicine, The Ottawa Hospital and University of Ottawa, Ottawa, ON, Canada

e-mail: dmcisaac@toh.ca

Ottawa Hospital Research Institute, Ottawa, ON, Canada

School of Epidemiology and Public Health, University of Ottawa, Ottawa, ON, Canada

Department of Anesthesiology \& Pain Medicine, The Ottawa Hospital, Civic Campus, Room B311, 1053 Carling Avenue, Ottawa, ON K1Y 4E9, Canada 
interventions with per patient cost of less than 2,600 CAD could be cost effective at the hospital level.

Trial

registration $w w w$. clinicaltrials.gov

(NCT03476707); registered 26 March, 2018.

\section{Résumé}

Objectif La prévalence de l'anémie est très élevée dans la population subissant une chirurgie colorectale, touchant 30-70\% des patients. L'anémie est associée à une morbidité et une mortalité importantes; toutefois, nous manquons de données probantes pour estimer les coûts des soins de santé associés à l'anémie. Cette étude avait pour but de déterminer les coûts hospitaliers de l'admission chirurgicale initiale, la durée de séjour postopératoire et le taux de transfusion associés à une anémie préopératoire lors de chirurgie colorectale majeure non urgente.

Méthode Cette étude de cohorte historique a inclus 851 patients adultes hospitalisés et subissant une chirurgie colorectale non urgente dans un réseau hospitalier universitaire de soins tertiaires entre avril 2010 et février 2016. L'anémie était définie comme un hématocrite $\leq 39$ $\%$. Le critère d'évaluation principal était les coûts hospitaliers totaux standardisés à la valeur du dollar canadien en 2016. Les critères d'évaluation secondaires étaient la durée de séjour postopératoire et les transfusions. Des analyses de régression multivariée et des évaluations par score de propension ont été utilisées pour mesurer les associations ajustées entre l'anémie et nos critères d'évaluation.

Résultats Avant la chirurgie, $381 / 851$ (45\%) patients étaient anémiques. Le coût moyen (écart type [ÉT]) de l'admission initiale pour une chirurgie colorectale non urgente était de 20040 (23 219) CAD. L'anémie a été associée à une augmentation relative ajustée de $14 \%$ des coûts (intervalle de confiance [IC] $95 \%, 6$ à 23; P< 0,001). Les coûts d'hospitalisation totaux attribuables à l'anémie étaient de 3027 CAD (IC 95 \%, 2670 à 3388). Les coûts hospitaliers et la durée de séjour étaient très fortement associés; l'anémie a été associée à une augmentation de $18 \%$ de la durée de séjour (IC $95 \%, 7$ à 30; $P<0,001$ ) et des taux de transfusion (risque relatif, 4,7; IC $95 \%, 2,71$ à 8,33; $P<0,001)$.

Conclusion Plus de 2600 CAD pour l'admission chirurgicale initiale sont attribuables à l'anémie préopératoire. Des interventions préopératoires ayant un coût par patient de moins de 2600 CAD pourraient être rentables au niveau hospitalier.

Enregistrement de l'étude $w w w$.clinicaltrials.gov (NCT03476707); enregistrée le 26 mars 2018.
Anemia is common in colorectal surgery patients, with a prevalence of $30-70 \% .^{1-3}$ The presence of anemia is associated with increased perioperative morbidity and mortality. ${ }^{3-6}$ In addition to the increased burden on the patient, anemia poses a burden on the healthcare system. Anemic patients are more likely to experience postoperative complications, which can add over 34,000 CAD to average surgical care costs. ${ }^{7}$ Anemic patients are also more likely to require blood transfusions, ${ }^{8}$ which cost over 666 CAD per unit in Canada, ${ }^{9}$ not including the potentially deleterious impact of avoidable transfusions on post-surgical and oncologic outcomes. ${ }^{6,10-12}$

Despite the high prevalence of anemia and robust evidence of anemia's association with adverse patient outcomes, there is little data to describe the costs attributable to anemia in colorectal surgery. Methods of treating preoperative anemia are well-established, including oral and intravenous iron, and erythropoietin therapy. ${ }^{13-15}$ These therapies reduce the rates of perioperative red blood cell (RBC) transfusion, but it is not clear if they are cost effective. ${ }^{13}$ Thus, understanding anemia-related costs is of key importance. In the United Kingdom, preoperative screening and intervention with iron treatment for anemia in elective knee and hip arthroplasty has saved 188 CAD per patient. ${ }^{16}$ Nevertheless, it is difficult to translate the findings of a small study of generally healthy orthopedic patients to colorectal surgery. Without robust colorectal-specific data, it is more challenging to determine economically feasible methods of preventing or treating preoperative anemia.

The primary outcome of this study was the adjusted hospital level costs attributable to preoperative anemia for the index surgical admission in elective colorectal surgery patients. The secondary outcomes were the association between preoperative anemia and postoperative length of stay (LOS) and rates of RBC transfusion.

\section{Methods}

This was a historical cohort study with ethics approval from the Ottawa Health Sciences Network Research Ethics Board (November 2017). As all data used were routinely collected, individual patient consent was waived. A study protocol was registered at ClincialTrials.gov (NCT03476707), and the analysis was conducted by the first author and overseen by the senior author. The manuscript is reported following STROBE and RECORD guidelines. ${ }^{17,18}$ 
Setting and data source

This study was conducted at The Ottawa Hospital (TOH), a tertiary care academic health sciences network and regional cancer referral centre with a catchment area of 1.2 million people. Colorectal surgical volumes are approximately 450 cases per year, and the majority of colorectal surgeons are fellowship trained. Patient data were collected from TOH's Data Warehouse, which stores all clinical and administrative data generated from episodes of care at $\mathrm{TOH}$. This database includes TOH's National Surgical Quality Improvement Program (NSQIP) data (prospectively collected by trained nurse abstractors using standard methods and definitions), the Canadian Institute for Health Information Discharge Abstract Database (hospitalization details, including procedures and diagnoses), the Surgical Information Management System (the perioperative electronic health record), and laboratory and pharmacy data. Standard procedures are routinely used to normalize and verify the accuracy of the Data Warehouse. ${ }^{19}$

\section{Selection and description of participants}

The study population included adult patients aged $18 \mathrm{yr}$ or older who underwent elective colorectal surgery between April 2010 (the start of TOH's NSQIP participation) and February 2016 (last date where all data were complete). Between 2010 and 2014, TOH only collected NSQIP Essentials data with a random $25 \%$ capture of patients. The NSQIP Procedure Targeted data were collected on all patients from 2015 and 2016. All data were de-identified. To ensure the anonymity of patients in this study, cell sizes with six or fewer patients were not reported. These included functional status, underweight, HIV positive status, ascites, dialysis, heart failure, and postoperative mortality. People with a non-elective route of admission were excluded. No changes in the care of anemic colorectal surgery patients occurred during the study period.

\section{Exposures}

Preoperative anemia was defined as a hematocrit less than $39 \%$, following previously published methods for NSQIP data. ${ }^{6}$

\section{Outcomes}

The primary outcome was hospital level cost of the index surgical admission. Costs were measured using standard and validated algorithms, standardized to $2016 \mathrm{CAD}^{20}$ This method accounts for a patient's resource intensity weight, their case mix group, as well as fixed patient costs (e.g., medications, investigations) and indirect costs to the hospital based on patient's location of care (intensive care unit [ICU] vs ward) and LOS. Resource intensity weight represents the relative resources used by an average patient in a case mix group and accounts for patients' medical complexity. As our study took the hospital's perspective, we did not account for physician fees, cost of readmissions, or non-administrative costs associated with blood transfusions (not paid by the hospital in Canada as blood product collection is funded by the federal government). Secondary outcomes were LOS (number of days from the day of surgery to the day of discharge), and the incidence of RBC transfusion (from the NSQIP file); RBC transfusion was defined as any transfusion during or after surgery.

\section{Technical information}

We calculated descriptive statistics (count and percent; mean and SD) for participants with and without anemia. Differences between groups were compared using the absolute standardized difference (ASD); values greater than $10 \%$ are considered to indicate a substantial difference. $^{21}$

Adjusted differences in costs were calculated using generalized linear regression with a log link and gamma distribution to account for skewness in cost data. ${ }^{22}$ The adjusted model included measured covariates that we postulated could confound the anemia-cost association and included American Society of Anesthesiology score (categorical $\leq$ II, III, $\geq$ IV), age (categorical per the NSQIP universal risk calculator $<65,65-74,75-84,>84$ $\mathrm{yr}),{ }^{23}$ functional status (binary independent $v s$ partially or totally dependent), Elixhauser comorbidity index (nominal), procedural index for mortality risk (PIMR) score (continuous linear per fractional polynomial analysis) ${ }^{24}$ and diabetes (categorical: none, oral medication, and insulin-dependent). We also included the following comorbidities as binary covariates: sex, hypertension, dyspnea with exertion or at rest, smoking, chronic obstructive pulmonary disease (COPD), disseminated cancer, thrombocytopenia (platelets < $\left.150 \times 10^{9} \mathrm{~L}^{-1}\right)$, and steroid use.

Our adjusted secondary analyses included the same covariates as the primary regression model. Red blood cell transfusion was analyzed using logistic regression, while LOS was analyzed using generalized linear regression with a log link and gamma distribution. ${ }^{25}$

Costs and LOS attributable to preoperative anemia were estimated by calculating the predicted costs and LOS for each participant based on the multivariable models described above. Five thousand bootstrap samples were then created using a 1:1 sampling rate to estimate the mean attributable cost and LOS, along with non-parametric 95\% 
confidence intervals (CI) by sampling the median, $2.5^{\text {th }}$ and $97.5^{\text {th }}$ percentiles of the bootstrap distribution of mean cost and LOS differences between those with and without anemia.

\section{Sensitivity analyses}

To test the robustness of our primary analysis, we conducted propensity score (PS) analyses using inverse probability of exposure weighting (IPW). We calculated PS using a logistic regression model to predict the presence of anemia, and included all variables specified in the primary adjusted model. An IPW was then calculated for each participant based on the PS. As recommended, IPWs below the $1^{\text {st }}$ percentile and above the $99^{\text {th }}$ percentile were trimmed. ${ }^{26}$

In Canada, the costs of purchasing blood products are not borne by the hospital. Therefore, the cost of RBCs were not included in our primary outcome except for the average 243 CAD in-hospital administration cost per unit of RBC. ${ }^{9}$ To test the impact of this omission, we added 423 CAD to the costs of each participant who received a transfusion (the estimated cost of producing a unit of RBCs in Canada). ${ }^{9}$ We then re-ran the primary regression with the transfusion-adjusted total cost as the dependent variable.

Post hoc, we evaluated the extent to which our hospital cost outcome was explained by LOS. We specified an ordinary least squares regression model with hospital costs as the dependent variable and LOS as the sole predictor variable. The R-squared value was calculated as an estimate of the extent to which variation in costs were explained by LOS.

Sample size and power

The study used all available data, so no a priori sample size calculation was performed. Typically, regression models with a continuous dependent variable can accommodate one covariate for every two participants. ${ }^{27}$ With 851 participants, we had greater than $99 \%$ power to detect a $30 \%$ difference in log-transformed costs.

Missing data

Exposure status was missing for $15(1.2 \%)$ patients, and outcome for $86(7.1 \%)$ patients. Our primary approach used complete case analysis, as our adjusted model also contained variables associated with missing data. ${ }^{28}$ Nevertheless, recognizing that missing data can contribute bias, we also re-ran our primary analysis using multiple imputations. Five imputation data sets were created using fully conditional predictive mean matching to impute missing cost outcomes, based on all variables included in the adjusted outcome models.

\section{Software}

All data manipulation and statistically analyses were performed with SAS Enterprise Guide 7.1 (SAS Institute, Cary, NC, USA).

\section{Results}

Study population

A sample of 1,206 patients undergoing colorectal surgery at TOH were captured in the NSQIP database between April 2010 and February 2016. Ninety-four patients were excluded because they were missing preoperative hematocrit values or total hospital costs. Two hundred sixty-one patients were excluded for undergoing colorectal
Figure Study inclusion and exclusion criteria

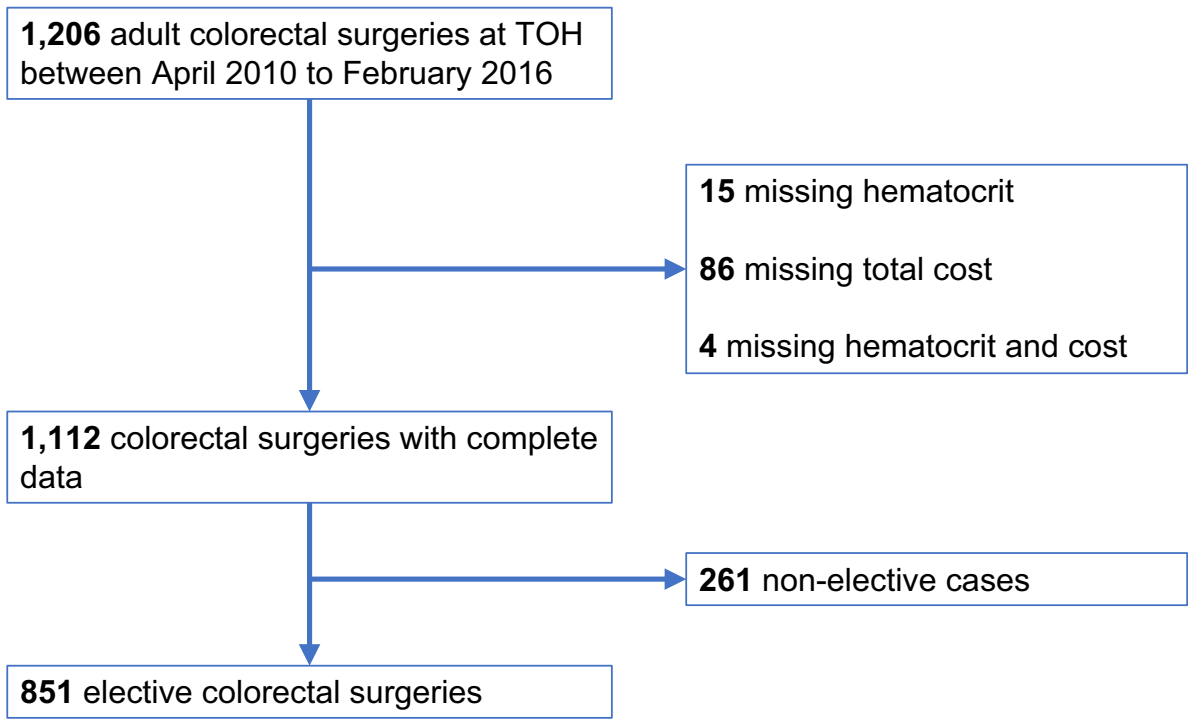


Table 1 Patient demographics and perioperative variables

\begin{tabular}{|c|c|c|c|}
\hline Variables & Non-anemic $(n=470,55.2 \%$ of total population $)$ & Anemic $(n=381,44.8 \%$ of total population) & $\overline{\mathrm{ASD}}$ \\
\hline Female, $n(\%)$ & $181(38.5)$ & $214(56.2)$ & 0.36 \\
\hline \multicolumn{4}{|l|}{ Age, $n(\%)$} \\
\hline$<65$ & $272(57.9)$ & $123(32.3)$ & 0.53 \\
\hline $65-74$ & $117(24.9)$ & $105(27.6)$ & 0.06 \\
\hline $75-84$ & $67(14.3)$ & $114(29.9)$ & 0.38 \\
\hline$>84$ & $14(3.0)$ & $39(10.2)$ & 0.3 \\
\hline Independent functional status, $n(\%)$ & $467(99.4)$ & $353(92.7)$ & 0.35 \\
\hline $\begin{array}{l}\text { Elixhauser comorbidity index (mean, } \\
\text { SD) }\end{array}$ & $5.50(5.89)$ & $6.16(5.98)$ & 0.12 \\
\hline PIMR score (mean, SD) & $0.17(0.70)$ & $0.47(1.39)$ & 0.49 \\
\hline \multicolumn{4}{|l|}{ ASA, $n(\%)$} \\
\hline I-II & $142(30.2)$ & $51(13.4)$ & 0.42 \\
\hline III & $302(64.3)$ & $260(68.2)$ & 0.08 \\
\hline IV-V & $26(5.5)$ & $70(18.4)$ & 0.4 \\
\hline Hypertension, $n(\%)$ & $196(41.7)$ & $203(53.3)$ & 0.23 \\
\hline Dyspnea, $n(\%)$ & $29(6.2)$ & $39(10.2)$ & 0.15 \\
\hline Smoker, $n(\%)$ & $97(20.6)$ & $46(12.1)$ & 0.23 \\
\hline $\mathrm{COPD}, n(\%)$ & $21(4.5)$ & $26(6.8)$ & 0.10 \\
\hline \multicolumn{4}{|l|}{ Diabetes, $n(\%)$} \\
\hline Non-insulin & $40(8.5)$ & $57(15.0)$ & 0.2 \\
\hline Insulin & $18(3.8)$ & $30(7.9)$ & 0.17 \\
\hline Disseminated cancer, $n(\%)$ & $44(9.4)$ & $44(11.5)$ & 0.07 \\
\hline Thrombocytopenia, $n(\%)$ & $26(5.5)$ & $24(6.3)$ & 0.03 \\
\hline Steroid use, $n(\%)$ & $31(6.6)$ & $28(7.3)$ & 0.03 \\
\hline
\end{tabular}

ASA = American Society of Anesthesiologist Physical Status Classification; ASD = absolute standardized difference; COPD = chronic objective pulmonary disease; PIMR = procedural index for mortality risk; SD = standard deviation

surgery for non-elective reasons. Ultimately, there were 851 adult elective colorectal surgery patients in the main analysis (Figure). Anemia was present in 381 participants $(44.8 \%)$. Individuals with anemia were more likely to be female, older, and have more comorbidities. Smokers were less likely to be anemic (Table 1). The mean (standard deviation [SD]) hospital cost of an elective colorectal surgery for all patients in this study was 20,040 $(23,219)$ CAD.

\section{Total hospital costs}

People without anemia had mean (SD) hospitalization costs of 17,100 (10,822) CAD compared with 23,667 (32,210) CAD for people with anemia. The adjusted regression model is presented in Table 2. Prior to adjustment, anemia was associated with a significant increase in costs (ratio of means [RM], $1.35 ; 95 \% \mathrm{CI}, 1.25$ to $1.46 ; P<0.001)$. Following adjustment for postulated confounders, anemia continued to be significantly associated with increased costs (RM, 1.14; 95\% CI, 1.06 to $1.23 ; P<0.001$ ) (Table 3). The attributable cost of anemia was estimated to be $3,027 \mathrm{CAD}$ (95\% CI, 2,664 to 3,397).

\section{Transfusion and LOS}

Transfusion rates and LOS were significantly higher in anemic patients prior to and post covariate adjustment (Table 3). The attributable LOS associated with anemia was 1.8 days $(95 \% \mathrm{CI}, 1.6$ to $2.0 ; P<0.001)$.

\section{Sensitivity analyses}

Propensity score-based IPW resulted in a balance of covariates (available as Electronic Supplementary Material, eTable 3). After trimming of extreme values, anemia was significantly associated with costs in our first sensitivity analysis (RM, 1.22; 95\% CI, 1.06 to $1.39 ; P=$ 0.004). Following the addition of the cost of packed RBC production, (estimated at $423 \mathrm{CAD}$ per patient transfused), there was a similar adjusted association between anemia and costs as in the primary analysis (RM, 1.14; 95\% CI, 1.06 to $1.23 ; P<0.001)$. Our multiple imputation analysis was consistent with all other analyses, with anemia being significantly associated with costs (RM, 1.14; 95\% CI, 1.06 
Table 2 Adjusted association of study covariates with total hospital cost

\begin{tabular}{|c|c|c|}
\hline Variables & Adjusted ratio of means $(95 \% \mathrm{CI})$ & $P$ value \\
\hline Anemia & $1.14(1.06$ to 1.23$)$ & $<0.001$ \\
\hline Female & $0.99(0.96$ to 1.03$)$ & 0.76 \\
\hline \multicolumn{3}{|l|}{ Age (yr) } \\
\hline$<65$ & Reference & \\
\hline $65-74$ & $1.03(0.89$ to 1.18$)$ & 0.70 \\
\hline $75-84$ & $0.96(0.81$ to 1.13$)$ & 0.60 \\
\hline$>84$ & 1.05 (0.81 to 1.36$)$ & 0.70 \\
\hline Independent functional status & $1.21(1.1$ to 1.34$)$ & 0.001 \\
\hline Elixhauser comorbidity index & $1.00(0.99$ to 1.01$)$ & 0.20 \\
\hline PIMR score & 1.08 (1.05 to 1.12$)$ & $<0.001$ \\
\hline \multicolumn{3}{|l|}{ ASA } \\
\hline I-II & Reference & \\
\hline III & 1.16 (1.04 to 1.32$)$ & $<0.001$ \\
\hline IV-V & 2.07 (1.67 to 2.57$)$ & $<0.001$ \\
\hline Hypertension & $1.02(0.98$ to 1.06$)$ & 0.37 \\
\hline Dyspnea & 1.01 (0.93 to 1.07$)$ & 0.93 \\
\hline Smoker & $1.02(0.97$ to 1.08$)$ & 0.47 \\
\hline COPD & 0.93 (0.86 to 1.02$)$ & 0.13 \\
\hline \multicolumn{3}{|l|}{ Diabetes } \\
\hline Non-diabetic & Reference & \\
\hline Non-insulin & 1.15 (0.96 to 1.38$)$ & 0.12 \\
\hline Insulin & 0.85 (0.67 to 1.09$)$ & 0.21 \\
\hline Disseminated cancer & $0.97(0.91$ to 1.03$)$ & 0.34 \\
\hline Thrombocytopenia & 0.78 (0.63 to 0.97$)$ & 0.03 \\
\hline Steroid use & $0.89(0.84$ to 0.97$)$ & 0.05 \\
\hline
\end{tabular}

ASA = American Society of Anesthesiologist Physical Status Classification; CI = confidence interval; COPD = chronic obstructive pulmonary disease; PIMR = procedural index for mortality risk; $\mathrm{RM}=$ ratio of means is defined as the relative difference in-hospital costs comparing those with anemia with those without. A value of 1.00 would indicate no difference in mean costs per hospitalization

Table 3 Unadjusted and adjusted association between anemia, hospital costs, postoperative red blood cell transfusion, and lengths of stay

\begin{tabular}{|c|c|c|c|c|c|c|}
\hline Outcomes & $\begin{array}{l}\text { Non-anemic }(n= \\
470)\end{array}$ & $\begin{array}{l}\text { Anemic }(\mathrm{n}= \\
381)\end{array}$ & $\begin{array}{l}\text { Unadjusted effect size } \\
(95 \% \mathrm{CI})\end{array}$ & $P$ value & $\begin{array}{l}\text { Adjusted effect size } \\
(95 \% \mathrm{CI})\end{array}$ & $P$ value \\
\hline Hospital costs, mean (SD) & $17,100(10,822)$ & $\begin{array}{l}23,667 \\
\quad(32,210)\end{array}$ & 1.35 (1.25 to 1.46$)$ & $<0.001$ & 1.14 (1.06 to 1.23$)$ & $<0.001$ \\
\hline $\begin{array}{l}\text { Postoperative red blood cell } \\
\text { Transfusion, } n(\%)\end{array}$ & $18(3.8)$ & $88(23.1)$ & 5.64 (3.31 to 9.63$)$ & $<0.001$ & 4.75 (2.71 to 8.33$)$ & $<0.001$ \\
\hline Length of stay, mean (SD) & $8.5(7.5)$ & $12.4(17.5)$ & $1.45(1.25$ to 1.71$)$ & $<0.001$ & $1.18(1.07$ to 1.3$)$ & $<0.001$ \\
\hline
\end{tabular}

The effect size of cost and length of stay represent ratio of means. The effect size of transfusion is a risk ratio. Cost is calculated in CAD. Length of stay is calculated in days. $\mathrm{CI}=$ confidence interval; $\mathrm{SD}=$ standard deviation

to $1.22 ; P=0.001)$. Length of stay explained the majority of variation in-hospital costs $\left(\mathrm{R}^{2}=0.89\right)$.

\section{Discussion}

In this single-centre cohort study of adult, elective colorectal surgery patients, anemia was highly prevalent and associated with a significant increase in index surgical admission costs in our primary analysis and across a variety of sensitivity analyses. Adjusting for confounders, we estimate that a $14 \%$ increase in-hospital costs, equivalent to 3,027 CAD (95\% CI, 2,664 to 3,397), may be attributable to preoperative anemia. Additionally, anemic patients were more likely to require $\mathrm{RBC}$ transfusion and have increased postoperative LOS. This study does not examine hospital costs associated with increased 90-day readmissions seen in anemic surgical 
patients $^{29}$ or system level costs, which would likely increase our estimate significantly. Given the high prevalence of anemia in colorectal surgery patients, and the associated risk of complications and increased costs of care, systematic preoperative optimization of anemic patients is likely warranted, and our findings provide important insights into estimating the cost effectiveness of such interventions.

The prevalence of anemia in our study was consistent with colorectal surgery literature, ${ }^{1-3}$ and was significantly higher than the rate found in most major non-cardiac surgeries. ${ }^{6}$ Colorectal surgery also accounts for the greatest share of adverse postoperative events in general surgery. ${ }^{30}$ Therefore, identifying modifiable, related risk factors can inform ongoing efforts to improve quality and outcomes in colorectal surgery. To date, many cost improvement studies in colorectal surgery have focused on enhanced recovery after surgery (ERAS) protocols, which typically decrease healthcare costs. ${ }^{31,32}$ Nevertheless, ERAS tends to place significant focus on intraoperative and postoperative processes. While optimizing intraoperative and postoperative care remain important goals, up to $86 \%$ of hospital costs are related to patient factors, with less than $10 \%$ being directly attributable to specific surgical practices. ${ }^{33}$ Based on our findings, emphasizing optimization of a prevalent and modifiable preoperative patient factor such as preoperative anemia could represent an avenue to reduce healthcare costs.

Anemia may contribute to increased costs through a variety of mechanisms. In part, increased rates of transfusion will increase transfusion-related costs, including costs associated with procurement, supplychain management, and patient administration of blood products. Nevertheless, our sensitivity analysis including procurement costs suggests the relative increase in anemiarelated costs was not substantially different than when blood procurement costs were not included. This suggests that factors aside from blood transfusion drive the increased costs of care, a finding consistent with literature demonstrating an independent association between preoperative anemia and postoperative morbidity and mortality. ${ }^{4,34,35}$ Anemia and transfusions are both risk factors for surgical site infections, which are cost drivers. Transfusions can also lead to other complications, such as immunologic reactions and volume overload, which require further medical management and increase costs

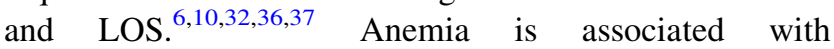
postoperative cardiac complications and renal failure in a dose-responsive manner., ${ }^{3,6}$ The extra 1.8 days that anemic patients stay compared with non-anemic patients in our study likely reflects such complications and contributes to increased hospital costs. ${ }^{36}$ The average LOS identified in this study (10.2 days) is notably longer than the average
LOS quoted by a recent meta-analysis for both ERAS (5.8 days) and non-ERAS (8.0 days) colorectal patients. ${ }^{38}$ This finding may be a function of the referral patterns to $\mathrm{TOH}$, which include a large volume of pelvic exenterations for advanced rectal cancers and may increase the average complexity of cases done at the centre compared with other ERAS centres.

The major etiology of anemia in colorectal surgery patients is iron deficiency secondary to gastrointestinal bleeding. ${ }^{1,39}$ Nevertheless, other causes of anemia, such as chronic disease, chemotherapy, radiotherapy, and nutrient deficiency are also common. ${ }^{1}$ While our observational study cannot prove a causal relationship between anemia and costs, or direct evidence that correcting preoperative anemia will lead to decreased costs, we do provide important data to guide future cost-effectiveness studies. Iron deficiency anemia can be addressed in colorectal cancer surgery patients using therapies such as oral or intravenous iron replacement, depending on the wait time to surgical resection that provides sufficient time for erythropoiesis. ${ }^{1}$ Even with an element of anemia secondary to chemotherapy and chronic disease, there is often a concurrent and reversible iron deficiency component. ${ }^{40}$ Nevertheless, current therapies such as intravenous iron and erythropoietin also have associated costs including start-up, lab work, medication, and preoperative clinic visits. ${ }^{41}$ Other studies have estimated a cost of 340 USD per patient for intravenous iron therapy. ${ }^{16}$ Studies of patient blood management programs in elective joint arthroplasty patients have shown decreases in LOS, postoperative transfusion rates, 90-day readmission rates, and healthcare system savings of 188 USD per patient. ${ }^{16,29,42}$ Nevertheless, in colorectal surgery where anemia rates and causes differ, and where longer waits from optimization must be balanced against risk of oncologic progression, these findings are not generalizable. Our results suggest that if per patient costs are below our conservative calculation of 2,600 CAD, then hospital cost savings may be realized. The ongoing PREVENTT trial will provide insights into the efficacy of preoperative intravenous iron therapy on transfusion rates; nevertheless, resource-use outcomes are secondary. Further analyses will be required to address the cost effectiveness of oral and intravenous iron therapy before colorectal surgery. These analyses will need to consider the role of other anemia treatment modalities such as erythropoietin, ${ }^{43}$ and move beyond considerations of simple costs by including patient-reported outcomes such as quality of life. 
Strengths and limitations

Our study should be assessed in keeping with its strengths and limitations. Our exposure and outcome variables were based on a clinical measurement and a validated patientlevel costing algorithm, respectively. The study was adequately powered, and we were able to control for a robust set of postulated confounders, including validated risk scores and prospectively collected comorbidities that were measurable in our linked clinical and administrative data. We also used best practice recommendations for regression analysis, and findings were consistent across all pre-specified sensitivity analyses. Nevertheless, as a single centre study, our findings may not be generalizable to other jurisdictions with different hospital funding models. As an observational study, our findings provide only an association between anemia and costs. There is risk of confounding bias due to unmeasured variables that might influence the presence of anemia or the accumulation of costs. In particular, neither the NSQIP data nor the hospital data included cancer stage or grade. The lack of integration of transfusion costs in our healthcare system required us to estimate the added cost of transfusions, and we were also unable to account for physician remuneration costs. Finally, our analysis was unable to account for the potential divergence in healthcare costs between anemic and non-anemic patients following hospital discharge. When factoring in these unaccounted system level costs, it is reasonable to expect that this study substantially underestimates the total increase in costs associated with preoperative anemia.

\section{Conclusion}

Anemia is a known risk factor for postoperative morbidity and mortality in colorectal surgery. ${ }^{3-6,8}$ This study demonstrates that there is also an increased hospital cost associated with preoperative anemia. In combination, these data provide motivation at the patient, hospital, and system levels to address anemia before surgery. While further studies are needed to causally demonstrate the role of available therapies to improve anemia-related adverse outcomes, our data suggest that therapies with costs less than 2,600 CAD may be cost-effective in the treatment of preoperative anemia.

Conflicts of interest None declared.

Editorial responsibility This submission was handled by Dr. Philip M. Jones, Associate Editor, Canadian Journal of Anesthesia.

Author contributions Simon Feng and Daniel I. McIsaac contributed to all aspects of this manuscript, including study conception and design, acquisition, analysis, and interpretation of data, and drafting the article. Joshua Greenberg, Husein Moloo, and Kednapa Thavorn contributed to the conception and design of the study and interpretation of data. Kednapa Thavorn contributed to the analysis of data.

\section{References}

1. Muñoz M, Gómez-Ramírez S, Martín-Montañez E, Auerbach M. Perioperative anemia management in colorectal cancer patients: a pragmatic approach. World J Gastroenterol 2014; 20: 1972-85.

2. Aydinli HH, Benlice C, Ozuner G, Gorgun E, Abbas MA. Risk factors associated with postoperative morbidity in over 500 colovesical fistula patients undergoing colorectal surgery: a retrospective cohort study from ACS-NSQIP database. Int J Colorectal Dis 2017; 32: 469-74.

3. Leichtle SW, Mouawad NJ, Lampman R, Singal B, Cleary RK. Does preoperative anemia adversely affect colon and rectal surgery outcomes? J Am Coll Surg 2011; 212: 187-94.

4. Musallam KM, Tamim HM, Richards T, et al. Preoperative anaemia and postoperative outcomes in non-cardiac surgery: a retrospective cohort study. Lancet 2011; 378: 1396-407.

5. Beattie WS, Karkouti K, Wijeysundera DN, Tait G. Risk associated with preoperative anemia in noncardiac surgery: a single-center cohort study. Anesthesiology 2009; 110: 574-81.

6. Wu WC, Schifftner TL, Henderson WG, et al. Preoperative hematocrit levels and postoperative outcomes in older patients undergoing noncardiac surgery. JAMA 2014; 297: 2481-8.

7. Vonlanthen $R$, Slankamenac K, Breitenstein $S$, et al. The impact of complications on costs of major surgical procedures: a cost analysis of 1200 patients. Ann Surg 2011; 254: 907-13.

8. Feng S, Machina M, Beattie WS. Influence of anaemia and red blood cell transfusion on mortality in high cardiac risk patients undergoing major non-cardiac surgery: a retrospective cohort study. Br J Anaesth 2017; 118: 843-51.

9. Lagerquist $O$, Poseluzny D, Werstiuk $G$, et al. The cost of transfusing a unit of red blood cells: a costing model for Canadian hospital use. ISBT Sci Ser 2017; 12: 375-80.

10. Acheson AG, Brookes MJ, Spahn DR. Effects of allogeneic red blood cell transfusions on clinical outcomes in patients undergoing colorectal cancer surgery:aA systematic review and meta-analysis. Ann Surg 2012; 256: 235-44.

11. Talukder Y, Stillwell AP, Siu SK, Ho YH. Comparing survival and recurrence in curative stage I to III colorectal cancer in transfused and nontransfused patients. Int Surg 2014; 99: 8-16.

12. Kulik U, Schrem H, Bektas H, Klempnauer J, Lehner F. Prognostic relevance of hematological profile before resection for colorectal liver metastases. J Surg Res 2016; 206: 498-506.

13. Muñoz M, Gõmez-Ramírez S, Cuenca J, et al. Very-short-term perioperative intravenous iron administration and postoperative outcome in major orthopedic surgery: a pooled analysis of observational data from 2547 patients. Transfusion 2014; 54: 289-99.

14. Schröder $O$, Mickisch $O$, Seidler $U$, et al. Intravenous iron sucrose versus oral iron supplementation for the treatment of iron deficiency anemia in patients with inflammatory bowel disease-a randomized, controlled, open-label, multicenter study. Am J Gastroenterol 2005; 100: 2503-9.

15. Lidder $P G$, Sanders $G$, Whitehead $E$, et al. Pre-operative oral iron supplementation reduces blood transfusion in colorectal surgery a prospective, randomised, controlled trial. Ann R Coll Surg Engl 2007; 89: 418-21. 
16. Pujol-Nicolas A, Morrison R, Casson C, et al. Preoperative screening and intervention for mild anemia with low iron stores in elective hip and knee arthroplasty. Transfusion 2017; 57: 304957.

17. von Elm E, Altman DG, Egger M, Pocock SJ, Gotzsche PC, Vandenbroucke JP. The Strengthening the Reporting of Observational Studies in Epidemiology (STROBE) statement: guidelines for reporting observational studies. Ann Intern Med 2007; 147: 573-7.

18. Benchimol EI, Smeeth L, Guttmann A, et al. The REporting of studies Conducted using Observational Routinely-collected health Data (RECORD) statement. PLoS Med 2015; 12: e1001885.

19. McIsaac DI, Abdulla K, Yang H, et al. Association of delay of urgent or emergency surgery with mortality and use of health care resources: a propensity score-matched observational cohort study. CMAJ 2017; 189: E905-12.

20. Wodchis WP, Bushmeneva $K$, Nikitovic M, McKillop I. Guidelines on Person-Level Costing Using Administrative Databases in Ontario - Working Paper Series, Volume 1, May 2013. Available from URL: http://www.hsprn.ca/uploads/files/ Guidelines_on_PersonLevel_Costing_May_2013.pdf (accessed January 2019).

21. Austin PC. Using the standardized difference to compare the prevalence of a binary variable between two groups in observational research. Commun Stat Simul Comput 2009; 38: 1228-34.

22. Austin PC, Ghali WA, Tu JV. A comparison of several regression models for analysing cost of CABG surgery. Stat Med 2003; 22 : 2799-815.

23. Bilimoria $K Y$, Liu $Y$, Paruch $J L$, et al. Development and evaluation of the universal ACS NSQIP surgical risk calculator: a decision aid and informed consent tool for patients and surgeons. J Am Coll Surg 2013; 217: 833-42.e1-3.

24. Sauerbrei $W$, Royston $P$. Building multivariable prognostic and diagnostic models: transformation of the predictors by using fractional polynomials. J R Stat Soc Ser A 1999; 162: 71-94.

25. Austin PC, Rothwell DM, Tu JV. A comparison of statistical modeling strategies for analyzing length of stay after CABG surgery. Health Serv Outcomes Res Methodol 2002; 3: 107-33.

26. Austin PC, Stuart EA. Moving towards best practice when using inverse probability of treatment weighting (IPTW) using the propensity score to estimate causal treatment effects in observational studies. Stat Med 2015; 34: 3661-79.

27. Austin PC, Steyerberg EW. The number of subjects per variable required in linear regression analyses. J Clin Epidemiol 2015; 68: 627-36.

28. Sterne JA, White IR, Carlin JB, et al. Multiple imputation for missing data in epidemiological and clinical research: potential and pitfalls. BMJ 2009; 338: b2393.

29. Frew N, Alexander D, Hood J, Acornley A. Impact of a blood management protocol on transfusion rates and outcomes following total hip and knee arthroplasty. Ann R Coll Surg Engl 2016; 98: 380-6.

30. Schilling PL, Dimick JB, Birkmeyer JD. Prioritizing quality improvement in general surgery. J Am Coll Surg 2008; 207: 698704.
31. Thiele RH, Rea KM, Turrentine FE, et al. Standardization of care: impact of an enhanced recovery protocol on length of stay, complications, and direct costs after colorectal surgery. J Am Coll Surg 2015; 220: 430-43.

32. Keenan JE, Speicher PJ, Thacker JK, Walter M, Kuchibhatla M, Mantyh CR. The preventive surgical site infection bundle in colorectal surgery: an effective approach to surgical site infection reduction and health care savings. JAMA Surg 2014; 149: 104552.

33. Gani F, Hundt J, Daniel M, Efron JE, Makary MA, Pawlik TM. Variations in hospitals costs for surgical procedures: inefficient care or sick patients? Am J Surg 2017; 213: 1-9.

34. Potter LJ, Doleman B, Moppett IK. A systematic review of preoperative anaemia and blood transfusion in patients with fractured hips. Anaesthesia 2015; 70: 483-500.

35. Wong CJ, Vandervoort MK, Vandervoort SL, et al. A clusterrandomized controlled trial of a blood conservation algorithm in patients undergoing total hip joint arthroplasty. Transfusion 2007; 47: 832-41.

36. Steele SR, Bleier J, Champagne B, et al. Improving outcomes and cost-effectiveness of colorectal surgery. J Gastrointest Surg 2014; DOI: https://doi.org/10.1007/s11605-014-2643-9.

37. Doumouras AG, Saleh F, Tarride JE, Hong D. A populationbased analysis of the drivers of short-term costs after bariatric surgery within a publicly funded regionalized center of excellence system. Surg Obes Relat Dis 2015; 12: 1023-31.

38. Greco M, Capretti G, Beretta L, Gemma M, Pecorelli N, Braga $M$. Enhanced recovery program in colorectal surgery: a metaanalysis of randomized controlled trials. World J Surg 2014; 38: 1531-41.

39. Wilson MJ, Dekker JW, Harlaar JJ, Jeekel J, Schipperus M, $Z$ waginga JJ. The role of preoperative iron deficiency in colorectal cancer patients: prevalence and treatment. Int $\mathbf{J}$ Colorectal Dis 2017; 32: 1617-24.

40. Steensma DP, Sloan JA, Dakhil SR, et al. Phase III, randomized study of the effects of parenteral iron, oral iron, or no iron supplementation on the erythropoietic response to darbepoetin alfa for patients with chemotherapy-associated anemia. J Clin Oncol 2011; 29: 97-105.

41. Kleineruschkamp A, Meybohm P, Straub N, Zacharowski K, Choorapoikayil $S$. A model-based cost-effectiveness analysis of patient blood management. Blood Transfus 2018; DOI: https:// doi.org/10.2450/2018.0213-17.

42. Kotzé A, Carter LA, Scally AJ. Effect of a patient blood management programme on preoperative anaemia, transfusion rate, and outcome after primary hip or knee arthroplasty: a quality improvement cycle. Br J Anaesth 2012; 108: 943-52.

43. Richards $T$, Clevenger B, Keidan $J$, et al. PREVENTT: preoperative intravenous iron to treat anaemia in major surgery: study protocol for a randomised controlled trial. Trials 2015; 16: 254.

Publisher's Note Springer Nature remains neutral with regard to jurisdictional claims in published maps and institutional affiliations. 